\title{
Drafting land allocation projects for urban development based on GIS technologies
}

\author{
Allabergan Babajanov ${ }^{1 *}$, and Rashid Abdiramanov ${ }^{2}$ \\ ${ }^{1}$ Tashkent Institute of Irrigation and Agricultural Mechanization Engineers, Tashkent, Uzbekistan \\ ${ }^{2}$ Tashkent Institute of Irrigation and Agricultural Mechanization Engineers, Tashkent, Uzbekistan
}

\begin{abstract}
The article scientifically describes the development of land allocation projects for urban purposes using geographic information systems (GIS) technology, one of the main forms of inter-farm land management, one of the state measures aimed at rational organization of land use. In addition, the scientific article should take into account the formation of the databases necessary for the development of such projects, the stages of data processing and analysis, as well as the issues that need to be addressed, as well as the development of feasibility studies for the implementation of such projects - key factors and key indicators, as well as expected project results.
\end{abstract}

\section{Introduction}

In the system of land use in the Republic of Uzbekistan, a special role is given to inter-farm land management, since this is the creation of various agricultural or non-agricultural land or land use, the boundaries of existing ownership of agricultural land, for various purposes. Allocation of land plots, allocation of corresponding changes in the boundaries of territorial units, allocation of special land plots for large hydraulic structures and structures. Several measures have been taken to protect the soil and the environment.

Of course, all this is based on existing and comprehensive projects. Therefore, in the shortest possible time, using GIS technologies for the development of integrated (economic, social, technical, environmental) interagency land management projects, for example, including the land allotment projects for sewage treatment plants in large cities, is particular importance. Because of the general features of such a complex project, including a specific goal, determination, efficiency, the need to take into account a large number of interrelated factors and their coordination require an integrated approach to time and financial constraints.

Recognizing that improving the supply of clean drinking water to the country's cities and villages is one of the main directions of the republic's domestic policy, the need for comprehensive land allocation projects for the construction and operation of such stations is once again demonstrated.

The purpose of the study is to highlight the main aspects of the use of GIS technology in the development of inter-farm land management projects related to land allocation and

*Corresponding author: r.abdiramanov@mail.ru 
comprehensive justification for the construction of a wastewater treatment plant, which aims to increase the efficiency of wastewater treatment and drinking water use.

The geo-information system technology is rapidly entering all aspects of human society. Today, it remains difficult to find an area where these technologies have not penetrated. Its rapid penetration allows us to find the simplest and most effective ways to positively address the existing problems in this area. Therefore, the development and implementation of various projects based on or using such technologies is a great practical importance for sectors of the economy. Thus, the theoretical study and research of control and monitoring of GIS-based projects and the necessity for these measures form the basis of the following issue.

\section{Methods}

Today, the design and research projects based on GIS technologies implemented in Uzbekistan by various design or research organizations are becoming increasingly important since GIS contributes to financial and labour costs. GIS is considered a modern computer technology that can be used to map and analyse real objects and investigate events in the life and activities of the population living in this area. [1,2,3]. Today, GIS is successfully used in various areas of our lives, especially in industry, transportation services, agriculture, and location of complex engineering communications in the regions, field development and management of such activities [4]. Therefore, the proper planning of GIS projects related to inter-farm land use, and especially the allocation of relatively large land plots for municipal economy purposes, will ensure the effective development of interfarm land management projects and their effective implementation tomorrow. Thus, when developing and justifying inter-farm land management projects using GIS technologies, we use the methods of variability, analytical analysis and monographic research.

\section{Results and discussions}

When planning any GIS project, the project goal is determined, the project database is formed, and the GIS functions are created using the analytical model to achieve the project objectives and analysis results; that is, the project consists of several stages. Therefore, it would be advisable to take several steps in GIS projects to allocate land for the construction of large urban wastewater treatment plants.

Step 1. Definition of the main aim. This is the initial step in the design process, the purpose of which is to determine the main goals and objectives. To define tasks, the following questions must be answered: What is the task? How is this solved today? What are the alternative ways to solve GIS? What should be the end result of the project? Are there enough data and maps for a quality project? Who are the users of the design results? Do others use this design information? What are the design requirements?

This step is important in the development of GIS-based urban land allocation projects, as the answers to the above questions will determine the size of the project and the methods to be used in its implementation.

Step 2. Creating a project database. Information is the basis of the system, without which the system does not work and does not exist at all [5]. This means that to develop a project, it is necessary to collect information and create a database. It should consist of three stages: creating a database, entering and loading the collected data, and managing the database.

Creating a database includes analysing the spatial data that we need for analytical requirements, determining the necessary attributes of objects, determining the boundaries 
that need to be investigated, and determining a coordinate system. Data entry includes digitizing previously collected and processed information and changing them to other formats that we can use and data verification and error correction. Defining a coordinate system and combining adjacent layers represent database management. As a rule, creating a database is the most complex and time-consuming part of any project, especially a land acquisition project, as it provides the information needed to select a land plot, including area, topography, soil, and the previous owner, environmental conditions, the availability of engineering infrastructure in the area and several other data. The accuracy of the analysis results is determined by the accuracy of the data used for this period.

Step 3. Data analysis and evaluation of results.

It is well known that data analysis using GIS technology ranges from simple mapping to complex spatial modelling. According to scientific sources, the model reflects the real world used to model processes, predict results, or analyse problems. The use of one or three categories of GIS functions in several spatial data leads to spatial modelling. Such GIS features include:

- geometric modelling functions;

- measuring distances, creating buffers and calculating areas and perimeters;

- cost modelling functions;

- integration of data sets to search for graphs of values that overlap;

- proximity modelling functions, i.e., zoning, search, placement.

The application of GIS in inter-farm land management projects, especially in the allocation of land for urban purposes, shows that quick and accurate results of previously impracticable or manual long-term analysis (land selection, project allocation, and multiple allocations of land) will be possible. By changing the methods and parameters of GIS use and reprocessing the analysis, it is possible to create several similar views of the land allocation project.

Evaluation of the results obtained in the analysis process is also one of the important steps of such projects. In this case, the use of economic-statistical methods, particularly the method of correlation, which reflects the correlation of the results with the factors, has a positive effect.

Step 4. Presentation of the results.

The results of the analytical work performed using GIS technology in the process of inter-farm land use, particularly non-agricultural land distribution, are often reflected on the map of the land management project. However, when using a GIS, it is important to know the charts and report types for the selected data reflection data. You can create graphs, charts and reports separately, insert them into documents created in other applications or place them separately on maps.

Thus, we have already learned about the successive stages of the development of interfarm land-use projects, especially urban land allocation projects using GIS technologies. Based on this introduction, we can now begin planning GIS projects at specific sites. It is desirable that project planning be carried out concerning an object clearly identified at the above stages. With this in mind, we will consider using GIS technology in the design of a site for a new wastewater treatment plant in Tashkent. This work usually begins with planning.

Planning is an important step in any project $[6,7,8,11]$. This helps to spend as little time and effort as possible on developing, analysing, and displaying the required databases. The project phases identify the main objectives of the project, the aspects of the analysis, and the set of data needed to complete the work. At the same time, it is advisable to choose approaches to analysis and the type of final product.

Once this is done, it is advisable to develop a project database that will be developed and then work on small GIS analytical projects. You can also learn how to plan large GIS 
projects and use ArcGIS, ArcMap, and ArcCatalog programs during such projects. The choice of location for new construction, the steps that will be taken to conduct certain types of analysis, and the tools used will be typical of most GIS projects. In the above example, the main content of the project is the selection of a land plot suitable for the construction of a wastewater treatment plant [11].

As you know, the city of Tashkent is growing and expanding every year [9]. The construction of a new wastewater treatment plant and the improvement of secondary water supply are some of the issues that need to be addressed to ensure its further development at such a high rate. The municipality plans to protect water resources and increase the level of secondary water use to meet expected water consumption.
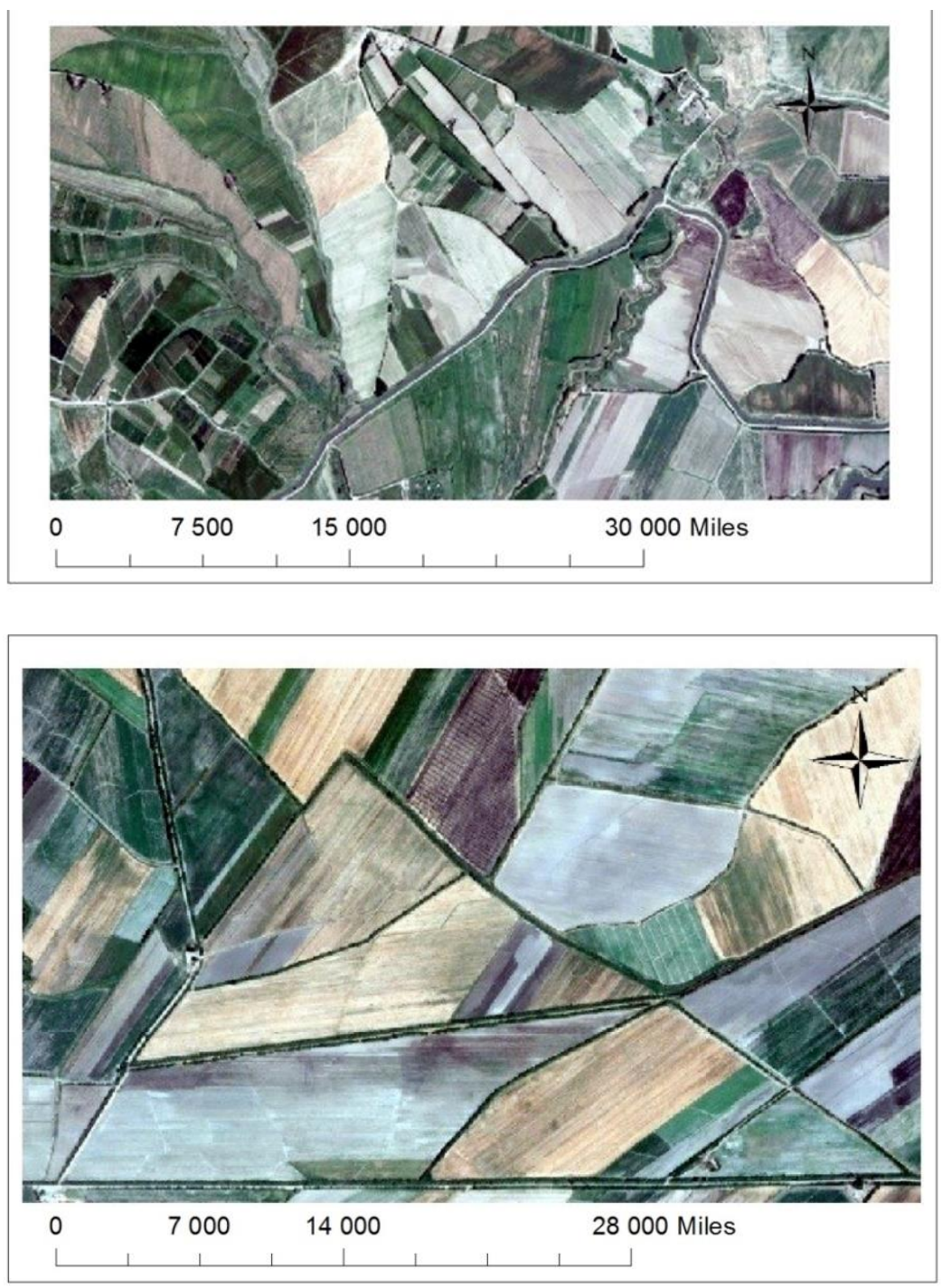

Fig. 1. Land allocation for a wastewater station based on GIS technology.

The main purpose of this GIS analysis is to identify and select a plot of land suitable for a wastewater treatment plant. The city administration has never used GIS technology to solve this problem. 
The location of the existing wastewater treatment plant was established many years ago using a paper map with transparent diagrams on it and consultations with the chief architect of the city and other leading experts. This process was timely but required considerable effort and time and did not allow the general public to make decisions. Currently, the problem is becoming more complicated due to the city's growth and increasing requirements for the environment and human health. The city administration decided to use GIS technology to speed up the process and ensure compliance with all requirements.

The municipality understands that the location of wastewater treatment plants is the most discussed issue, and it wants to identify all suitable sites and then the most suitable plots based on more stringent criteria. There is wider public participation in the discussion of all possible land plots. Therefore, you need a special map to clearly indicate which plots are suitable for this purpose. The government recommended a list of eligibility criteria. A review of the official data obtained showed that such criteria include:

- it should not be above $400 \mathrm{~m}$ above sea level to prevent the flow of water;

- it must be located outside the drinking water zone to ensure the normal discharge of fresh water;

- it should be at least $1000 \mathrm{~m}$ from the river to minimize the cost of flow through the pipeline;

- treatment facilities should be located at least $150 \mathrm{~m}$ from residential areas and parks to reduce discomfort for urban residents;

- Where possible, there should be a free, non-agricultural plot of land for the station.

In addition, the role of the land selected and allocated to reduce future costs should be:

- at least $500 \mathrm{~m}$ from the sewer networks;

- at least $50 \mathrm{~m}$ from the road network

Calculations showed that at least 20 hectares of land would be required to locate the station. To determine its location, you must first study the maps and other materials to determine the site's location. This area will be the project work area. Here, the analysis of GIS technology allows you to combine all the criteria for finding the right plot of land for the station's construction.

The next step in a GIS land acquisition project is to create a project database.

Creating a database for a land acquisition project would be desirable, in our opinion, in two parts. The first part is designed to collect and analyze existing data, and the next section is to prepare data for analysis. Only accurate data can be used, while others require additional processing. It is important to note here that the process of searching for the necessary information and its analysis based on GIS is very important since it is the key to a positive solution to the problem. Typically, there are several steps in preparing data for analysis. They can be divided into:

- verification of data quality (accuracy and relevance of data);

- change the data format;

- data entry, numbering, scanning, modification, geographical reference;

- determination of the coordinate system;

- providing a new coordinate system;

- merging adjacent layers [11].

The use of basic GIS technologies, in particular ArcGIS and ArcCatalog, has a positive impact on all these stages. In addition, data processing using these programs will allow for accurate analysis from both a scientific and a practical point of view, as well as make scientifically sound decisions. Processing data on land acquisition for constructing a new wastewater treatment plant using the ArcGIS program showed that it was $12 \mathrm{~km}$ from the city. It was found that an area that is not suitable for agriculture, $2 \mathrm{~km}$ from the existing station, is suitable land for constructing such a station. The new station's location in this 
section is fully consistent with the above requirements and does not have a negative impact on the environment.

It should be noted that it traditionally took almost 30 days to allocate and substantiate such land. The use of GIS technology has reduced the time required to solve this problem by 15 times. This means that, of course, material costs will also decrease by several times with a reduction in time.

Of course, the stages of processing and analysis of GIS data for the design and allocation of land for the construction of a sewage treatment plant and recycling in Tashkent are almost identical to all similar land management projects. Therefore, we can assume that the importance of such technologies in the future is extremely important.

It is important not only to develop projects but also to justify them. A GIS-based feasibility study is the project's feasibility study. This document is primarily necessary for the investor, as the investor makes the final decisions on capital investments to create and restore fixed assets based on this document. An investor is always thinking of investing in his or her unused cash flow in one sphere. It is important for him that he invested his money in the project, how important this project is for him, and how long the funds invested in the project will begin to benefit. These issues will be considered using the feasibility study of the project, particularly the inter-farm project for land management.

Suppose capital investments in fixed assets are fully or partially financed from the state budget or its extra-budgetary funds and own financial resources of state enterprises. In that case, the feasibility study is a mandatory document. The decision on the feasibility study of projects financed from other sources of financing is independently made by the investor (customer). Based on the results of our research, we have tried to identify the basic data needed to prepare a feasibility study for the implementation of the GIS project related to the allocation of land for the construction of a wastewater treatment plant, and we present it below. This list can be found in the feasibility study for other GIS-based projects:

1. Forecast of data on the long-term socio-economic development of the republic (for example, by 2030).

2. A copy of the decision of state and local authorities on the construction of the facility.

3. Information about the natural conditions, infrastructure, recreational and protective zones of the territory on which the land plot is allocated for construction.

4. Information about the possibility of using imported equipment at the facility.

5. Information on various environmental impacts resulting from the operation of the facility under construction.

6. Information on determining the optimal capabilities of a facility under construction.

7. The results of previous scientific and experimental design work on technological processes, devices and their improvement at the construction object.

8. Design and estimate documentation approved in an established manner, indicating the facility's construction area and the facility's location that will be connected to networks and communications.

9. Information on buildings and structures that will be demolished due to the construction of the facility on the allotted land, information on the number of resettled citizens and families.

10. Other information describing the characteristics of the facility under construction.

As a rule, the feasibility study of the project is intended to provide creditors or organizations with credit guarantees, financial stability and solvency, as well as tax and other incentives, subsidies, etc. [10]. The following is a summary of the feasibility study of the land allocation project:

- the basis for the development of a feasibility study;

- purpose of investment;

- description of the investment object; 
- information on the status of resources involved in the economic activities of the future enterprise;

- initial assessment and research results;

- information about the client, investor, potential contractors, suppliers of construction materials, as well as the contractor of the feasibility study;

- location of the enterprise;

- basic technical solutions (options);

- environmental impact assessment;

- human resources and social development;

- schedule for the implementation of the land allotment project;

- economic evaluation and analysis of the project;

- conclusions and recommendations;

- applications (engagement documents, graphic materials)

In the conditions of modern market competition, it is important to evaluate and justify the implementation of the project. In our opinion, this rule is especially important for GIS projects since geographic information systems are modern, complex and highly accurate in tasks. Therefore a special business plan will be developed to support them [11].

It is well known that the economic and social reforms carried out in the country in recent years are associated with the development of entrepreneurship and the creation of various production and service capacities based on large-scale investments in the economy. This, in turn, is directly related to the selection, distribution and legalization of suitable land for such facilities. At the same time, it is very important that these facilities are not damaged in the agricultural sector and engineering infrastructure. Therefore, we think that using GIS technologies, such as the above, will be very effective in solving all the problems of selection and allocation of land. Because GIS allows you to quickly analyse a large amount of data, identify the most optimal solutions, and develop a basic version of the project based on this optimal solution.

\section{Conclusion}

Thus, based on the research, it can be briefly concluded that the implementation of interfarm land management, especially the selection, allocation and registration of land plots for large urban purposes, which is one of its main issues with GIS-based projects, is labourintensive and reduces several times. Allows justifying the allotted land plot in all respects. At the same time, these technologies make it possible to draw sound conclusions, develop several options for choosing land and distributing land, as well as put into operation such projects and ultimately increase the efficiency of land use in the area.

The authors would like to express their deep gratitude to the organizers of the scientific conference in advance for acquainting and accepting the results of this modest scientific research on the development and justification of inter-farm land management projects based on GIS technologies.

\section{References}

1. E. Safarov, Technology of geographic information systems. Tashkent University, 2009

2. L. Guryanova, Downloaded to GIS. Mn., BSU, (2009)

3. I. Lurie, Geo-information Cartography. M., Moscow State University, Book House, (2008) 
4. S. Saidkasimov, Technology of geographic information systems. Tashkent, Economics Finance, (2011)

5. S. Lipsky, The problem is that all your problems are in the background. M., IP Kim L.A., (2019)

6. A. Babajanov, Project organization and management. Tashkent, Economics and Finance, (2016)

7. V. Shapirov, Modernization of projects / Ed. I.I. Mazur, - 6th edition - M.: Omega-L, (2010)

8. A Guide to the Project Management Body of Knowledge. Project Management Institute, (1996)

9. National Encyclopaedia of Uzbekistan. Volume 7. Tashkent, "National Encyclopaedia", (2006)

10. S. Avezboev, S. Volkov, Land management design (Textbook). Tashkent, New Generation, (2004)

11. A. Babajanov, R. Abdiramanov, I. Abdurahmanov, U. Islomov. Advantages of formation non-agricultural land allocation projects based on GIS technologies. E3S Web of Conferences, 227, (2021) 